\title{
Case Studies
}

\section{A Case of Adrenergic Urticaria Associated with Vitiligo}

\section{Caroline Lang Gürkan Kaya}

Division of Dermatology and Venereology, University Hospital of Geneva, Geneva, Switzerland

\section{Keywords}

Adrenergic urticaria $\cdot$ Vitiligo $\cdot$ Catecholamines

\begin{abstract}
Adrenergic urticaria is a rare form of urticaria, induced by a stress-induced concomitant release of epinephrine and norepinephrine. Here we describe the case of a 60-year-old female patient presenting with disseminated erythematous papules surrounded by a white halo and vitiligo lesions on the hands, arms, and feet. Histological examination of one of the erythematous papules showed a dermal inflammatory infiltrate composed of lymphocytes and eosinophils of perivascular and interstitial localization. After 2 weeks of treatment with antihistamines, the lesions disappeared completely.

\section{Introduction}

Adrenergic urticaria $(A U)$ is a rare form of urticaria. Only 12 cases have been reported in the medical literature [1-11]. It is characterized by pale skin surrounding small red to pink papules. Known trigger factors include emotional or physical stress, coffee, tea, chocolate, ginger, and aubergine $[1,2]$. Here we report a case of AU associated with vitiligo.

\section{Case Report}

A 60-year-old female patient presented with non-itchy rash. She had no associated symptoms. One week earlier, she had undergone surgery for a dental implant. She had no history of atopy or allergy. She had been known for a vitiligo for 10 years. On clinical exami- 

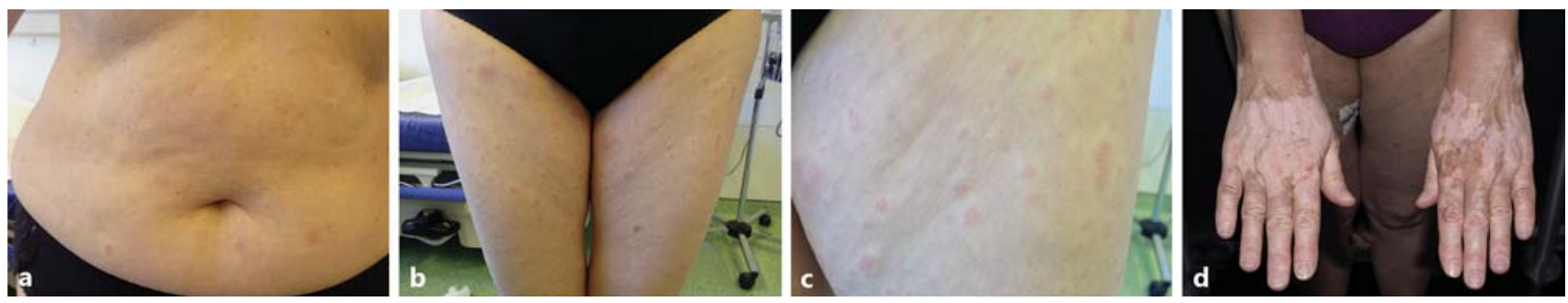

Fig. 1. Erythematous papules surrounded by a white halo on the abdomen (a) and thighs (b, c) and vitiligo lesions on the hands (d).

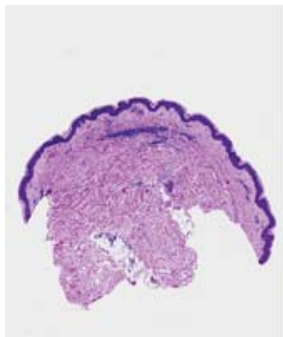

a
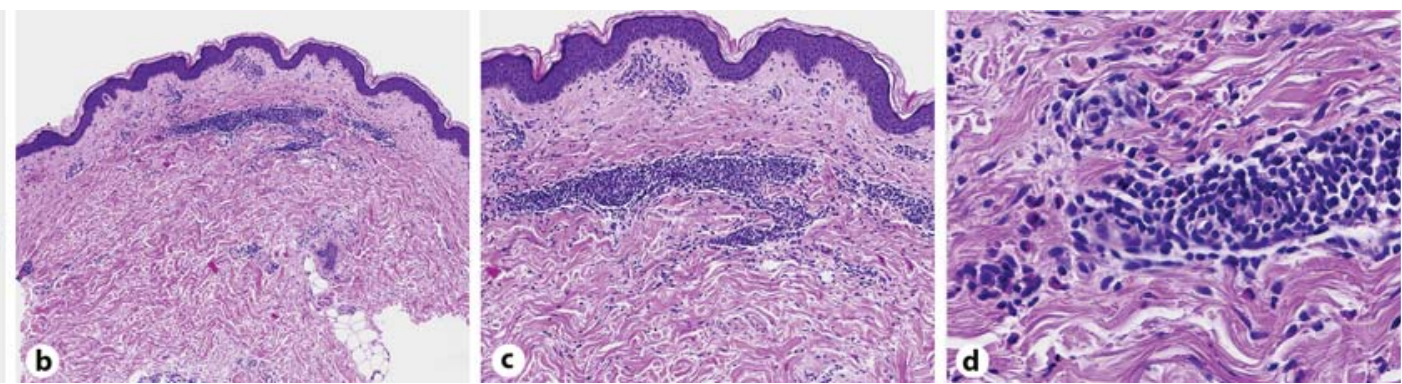

Fig. 2. Perivascular and interstitial dermal infiltrate of lymphocytes and eosinophils in the superficial and reticular dermis. Original magnification $1 \times(\mathbf{a}), 2 \times(\mathbf{b}), 5 \times(\mathbf{c})$, and $20 \times(\mathbf{d})$.

nation, she had disseminated 3-4 mm erythematous papules surrounded by a white halo, predominantly on the trunk and the limbs (Fig. 1). Vitiligo lesions were present on the hands, arms, and feet. Laboratory tests demonstrated normal complete blood cell count and biochemical values, including thyroid function. Histology showed a preserved epidermis and a dermal inflammatory infiltrate composed of lymphocytes and eosinophils of perivascular and interstitial localization (Fig. 2). She responded well to high doses of oral antihistamines with a complete disappearance of the lesions after 2 weeks.

\section{Discussion}

The pathogenesis of AU is poorly understood. Autoimmune disorders have been associated with AU (rheumatoid arthritis [9], thyroid autoimmune disorders [10], and positive anti-nuclear antibodies [2]). So far, only 1 other case of AU has been described in association with vitiligo [1] and 1 case with a family history of vitiligo [9]. Electron microscopy on skin biopsy of patients with AU shows mast cell degranulation, confirming that pathogenesis is regulated by mast cells. In most urticarias, mast cells are activated through IgE receptors. As in cholinergic urticaria where cholinergic nerves of the sympathetic nervous system release acetylcholine directly onto mast cells to initiate cell degranulation, a similar mechanism may operate in AU. It has been postulated that lesions of AU are induced by a stress-induced concomitant release of epinephrine (vasoconstriction corresponding to the white halo) and norepinephrine (mast cell degranulation leading to histamine release responsible for the central erythema and edema [12]). Laboratory tests performed in patients during episodes 
Lang and Kaya: A Case of Adrenergic Urticaria Associated with Vitiligo

of AU showed an elevated serum epinephrine, norepinephrine, and total catecholamines with normal serum histamine and inconsistently raised IgE levels $[1,2,4-6,10]$.

In vitiligo, increased catecholamine levels in skin and plasma have been observed [13, $14]$, as well as increased expression of $\beta_{2}$-adrenoceptors in differentiating epidermal keratinocytes [15]. Furthermore, mast cells, VEGF, and angiogenesis have been shown to be higher in vitiligo lesions [16].

The diagnosis of AU is basically clinical and histology is not specific. Intradermal injection of 5 ng adrenaline or 3-10 ng noradrenaline will reproduce the characteristic lesions and can confirm the diagnosis [4]. A white halo surrounding urticarial lesions may also be seen in arthropod bite reactions and in pruritic urticarial papules and plaques of pregnancy, when catecholamines are high.

Antihistaminic drugs usually have a limited effect, suggesting the histamine release by mast cells is not mainly linked to the activation of $\mathrm{H} 1$ or $\mathrm{H} 2$ mast cell receptors. Propanolol has been shown to be efficient in the treatment of AU, probably acting both on central $\beta$-adrenoreceptor and mast cell adrenergic receptors [4]. Oral clotiazepam was effective in a patient refractory to propranolol treatment, underlining the importance of the release of catecholamines in the pathogenesis of AU [11].

AU may not be as rare as widely thought, and dermatologists should be aware of this condition to avoid the misdiagnosis of more common cholinergic urticaria.

\section{Statement of Ethics}

The patient gave her informed consent for this publication.

\section{Disclosure Statement}

The authors have no conflicts of interest to disclose.

\section{References}

1 Shelley WB, Shelley ED: Adrenergic urticaria: a new form of stress-induced hives. Lancet 1985;2:1031-1033.

$>2$ Chedraoui A, Uthman I, Abbas 0, Ghosn S: Adrenergic urticaria in a patient with anti-double-stranded DNA antibodies. Acta Derm Venereol 2008;88:263-266.

3 Deacock SJ: An approach to the patient with urticaria. Clin Exp Immunol 2008;153:151-161.

-4 Haustein UF: Adrenergic urticaria and adrenergic pruritus. Acta Derm Venereol 1990;70:82-84.

5 Vithayasai P, Vithayasai V: Adrenergic urticaria: a first report from Thailand. J Med Assoc Thai 1989;72:478480.

6 Klebanova Y, LeGrys V, Cooper D, Levy D, Santora D, Schwindt C: A case of localized adrenergic urticaria mimicking an allergic reaction to a sweat chloride test. Pediatr Pulmonol 2009;44:935-938.

7 Maerens-Tchokokam B, Vigan M, Breuillard F, Vuitton DA, Girardin P, Laurent R: Guess what! Adrenergic urticaria. Eur J Dermatol 1999;9:137-138.

8 Mihara S, Hide M: Adrenergic urticaria in a patient with cholinergic urticaria. Br J Dermatol 2008;158:629631.

9 Capella GL: Adrenergic urticaria and rheumatoid arthritis in a patient with melanoma: an intricate medical management. J Drugs Dermatol 2012;11:409-412.

10 Wang Y, Yu J, Tu P: Adrenergic urticaria in a patient with atopic skin reaction and thyroid autoantibody. J Dermatol 2013;40:131-132.

11 Kawakami Y, Gokita M, Fukunaga A, Nishigori C: Refractory case of adrenergic urticaria successfully treated with clotiazepam. J Dermatol 2015;42:635-637.

12 Hogan SR, Mandrell J, Eilers D: Adrenergic urticaria: review of the literature and proposed mechanism. J Am Acad Dermatol 2014;70:763-766. 
Lang and Kaya: A Case of Adrenergic Urticaria Associated with Vitiligo

-13 Schallreuter KU, Wood JM, Ziegler I, Lemke KR, Pittelkow MR, Lindsey NJ, Gutlich M: Defective tetrahydrobiopterin and catecholamine biosynthesis in the depigmentation disorder vitiligo. Biochim Biophys Acta 1994; 1226:181-192.

14 Schallreuter KU: Beta-adrenergic blocking drugs may exacerbate vitiligo. Br J Dermatol 1995;132:168-169.

-15 Schallreuter KU, Wood JM, Pittelkow MR, Swanson NN, Steinkraus V: Increased in vitro expression of beta 2-adrenoceptors in differentiating lesional keratinocytes of vitiligo patients. Arch Dermatol Res 1993;285: 216-220.

16 Aroni K, Voudouris S, Ioannidis E, Grapsa A, Kavantzas N, Patsouris E: Increased angiogenesis and mast cells in the centre compared to the periphery of vitiligo lesions. Arch Dermatol Res 2010;302:601-607. 